\title{
Fall frequency and incidence of distal forearm fracture in the UK
}

\author{
T W O'Neill, J Varlow, J Reeve, D M Reid, C Todd, A D Woolf, A J Silman
}

\author{
ARC Epidemiology \\ Manchester \\ University, \\ Manchester M13 9PT \\ T W O'Neill \\ J Varlow \\ A J Silman
}

Bone Disease Reserve

Group,

MRC Clinical

Research Centre and

Northwick Park

Hospital,

Harrow

J Reeve

Department of

Rheumatology,

City Hospital,

Aberdeen

D M Reid

Health Services

Research Group

Institute of Public

Health,

University of

Cambridge

$C$ Todd

Department of

Rheumatology,

Royal Cornwall

Hospital,

Infirmary Hill,

Truro

A D Woolf

Correspondence to:

Dr T W O'Neill.

Accepted for publication June 1995

\begin{abstract}
Study objective - This analysis aimed to determine the frequency of falls in men and women aged 50 years and over and to explore whether age variation in fall frequency may explain variation in the incidence of distal forearm fracture in women.

Design - This was a cross sectional survey. Setting - Primary care based registers in four UK areas.

Participants - Altogether 501 men and 702 women age 50-79 years participated. Main results - A total of $131(26 \cdot 1 \%)$ men and $181(25 \cdot 8 \%)$ women reported falling in the previous year. In women, the frequency of falls rose with age ( $\chi^{2}$ test for trend 4.33; $p=0.04)$, with no obvious early postmenopausal peak or subsequent decline. Men aged 50-54 years had a significantly increased risk of falls compared with women of the same age group, (odds ratio $(\mathrm{OR})=2 \cdot 4 ; 95 \%$ confidence interval $(\mathrm{CI})$ $1 \cdot 3,4 \cdot 6)$, though above this age, the risk of falling was greater in women $(O R=1 \cdot 2$; 95\% CI 0.9, 1.5).

Conclusions - There are important differences in the frequency of falls in relation to age and sex. The data suggest that variation in fall frequency per se does not explain age variation in the incidence of distal forearm fracture in women.
\end{abstract}

\section{( $\mathcal{F}$ Epidemiol Community Health 1995;49:597-598)}

The descriptive epidemiology of falls has been well characterised in elderly populations but there are few data on the frequency of falls in populations which include men and women aged less than 65 years.

Winner $^{1}$ in a postal survey of Oxford city residents reported a one year fall frequency of $12-20 \%$ in men between 20 and 85 years. In women fall frequency was similar until the perimenopausal period when it rose to $32 \%$ before falling to $21 \%$ in women in their late 60 s, with a further increase after 75 years. Torgerson, ${ }^{2}$ in a population based sample of Aberdeen women aged 45-49 years, reported a fall frequency of $14 \%$.

In women, the incidence of distal forearm fracture increases rapidly during the early postmenopausal period and in most, ${ }^{34}$ though not all series, ${ }^{5}$ there is evidence of a plateau in incidence of fracture during the mid $60 \mathrm{~s}$. We have attempted to confirm whether an age variation in fall frequency may partly contribute to this observed pattern. ${ }^{1}$
Methods

The subjects who took part in this study were recruited from primary care based registers during the course of a large multicentre prevalence survey of vertebral osteoporosis in four UK centres (Aberdeen, Cambridge, Harrow, and Truro). Stratified random sampling was used with sex and five year age bands (50-54, $55-59,60-64,65-69,70-74,75+$ years) as stratification groups. Subjects were invited by letter to attend for a spinal radiograph and an interviewer administered questionnaire. A follow up letter was sent to those who failed to attend, usually within four weeks. The overall response rate was $55 \%$ excluding those known to have died or moved house. In the four centres, a consecutive sample of approximately $76 \%$ of participants was also invited to complete a short interviewer administered questionnaire concerning falls. Subjects were asked about the occurrence of falls: "Have you fallen in the last 12 months?" and, "If Yes, how many times". These questions were based on those used in a previously validated instrument. ${ }^{6}$

The proportions of subjects who reported a fall in the previous year were calculated in five year age and sex bands from 50 to 79 years. Because of small numbers, individuals aged 80 years and over were excluded from the analysis.

\section{Results}

Altogether 1203 subjects age $50-79$ years were recruited - 501 men (mean (SD) age $64 \cdot 5(8 \cdot 0)$ years) and 702 women (mean (SD) age 63.8 $(8 \cdot 0)$ years). In all, $312(25.9 \%)$ subjects reported falling in the previous year - 131 $(26.1 \%)$ men and $181(25 \cdot 8 \%)$ women. Of these, 39 men $(30 \%)$ and 68 women $(38 \%)$ reported falling on more than one occasion. The table shows the numbers and proportions of subjects who reported any fall in the previous year in relation to age and sex group.

In women, the frequency of falls rose with age ( $\chi^{2}$ test for trend $4 \cdot 33 ; p=0 \cdot 04$ ). Men aged $50-54$ years had a significantly increased risk of falls compared with women of the same age group, (odds ratio $(\mathrm{OR})=2 \cdot 4 ; 95 \%$ confidence interval (CI) $1.3,4 \cdot 6$ ) but above this age the risk of falling was slightly greater in women $(\mathrm{OR}=1 \cdot 2 ; 95 \%$ CI $0.9,1 \cdot 5)$.

\section{Discussion}

Winner suggested that changes in the risk of falling interact with osteoporosis and are partly responsible for the perimenopausal rise in the incidence of distal forearm fracture seen in women at this time and the fluctuations in 
Proportions of men and women who experienced a fall in the previous 12 months (by age group).

\begin{tabular}{|c|c|c|c|c|c|c|c|c|}
\hline \multirow{3}{*}{$\begin{array}{l}\text { Age } \\
\text { group } \\
(y)\end{array}$} & \multicolumn{4}{|l|}{ Men } & \multicolumn{4}{|c|}{ Women } \\
\hline & \multirow[t]{2}{*}{ No } & \multicolumn{3}{|l|}{ Falls } & \multirow[t]{2}{*}{ No } & \multicolumn{3}{|l|}{ Falls } \\
\hline & & No & $\%$ & (SEM) & & No & $\%$ & $(S E M)$ \\
\hline $\begin{array}{l}50-54 \\
55-59 \\
60-64 \\
65-69 \\
70-74 \\
75-79\end{array}$ & $\begin{array}{l}75 \\
96 \\
95 \\
97 \\
81 \\
57\end{array}$ & $\begin{array}{l}27 \\
20 \\
25 \\
23 \\
20 \\
16\end{array}$ & $\begin{array}{l}36 \\
21 \\
26 \\
24 \\
25 \\
28\end{array}$ & $\begin{array}{l}(5 \cdot 5) \\
(4 \cdot 1) \\
(4 \cdot 5) \\
(4 \cdot 3) \\
(4 \cdot 8) \\
(6 \cdot 0)\end{array}$ & $\begin{array}{r}121 \\
145 \\
128 \\
129 \\
110 \\
69\end{array}$ & $\begin{array}{l}23 \\
37 \\
30 \\
40 \\
28 \\
23\end{array}$ & $\begin{array}{l}19 \\
26 \\
23 \\
31 \\
26 \\
33\end{array}$ & $\begin{array}{l}(3 \cdot 6) \\
(3 \cdot 6) \\
(3 \cdot 7) \\
(4 \cdot 1) \\
(4 \cdot 2) \\
(5 \cdot 7)\end{array}$ \\
\hline Total & 501 & 131 & (26) & & 702 & 181 & (26) & \\
\hline
\end{tabular}

incidence in old age. ${ }^{1}$ In our study, apart from minor fluctuations, the fall frequency rose gradually with age in women. There was no obvious peak incidence of falls in the early postmenopausal period or a subsequent decline. Because of small numbers within individual age strata, the data do not, however, exclude a plateau in fall frequency after 65 years, nor a rise in fall incidence in postmenopausal compared with premenopausal women, as previously suggested. ${ }^{2}$

Differences in absolute fall frequency between this and Winner's series may be related to methodological differences in study design, such as the use of interviewers rather than postal questionnaire increasing recall, or they may be related to lifestyle or environmental differences in the populations studied.

The response rate for participation in the study (55\%) was moderate, though similar to that found in another large epidemiology study of osteoporosis conducted in the UK. ${ }^{7}$ We analysed responses from those recruited after a first letter of invitation with those recruited after the reminder. There were no significant differences in fall frequency between these groups. This provides some evidence against serious non-response bias but does not exclude this. The main focus of this survey was osteoporosis. Because of the relationship between osteoporosis and trauma it is possible that a recent fall may have prompted participation. It is unlikely, however, that this bias would affect the younger rather than the older women, and is unlikely therefore to have influenced the age pattern of falls.

The explanation for the excess risk of falls in young men is unclear. Occupational factors are possible. Some manual occupations are known to be associated with an increased risk of falls ${ }^{8}$ but we did not have information which would either confirm or refute this. There are few comparative data, although in a recent hospital based study in Denmark there was a slight excess of wrist trauma in men age $40-44 .^{9}$

Although falls are clearly involved in the pathogenesis of distal forearm fracture, and fall prevention programmes are likely to have a beneficial effect on reducing fracture rates, our data suggest that variation in fall frequency per se does not explain age differences in the incidence of this fracture in women.

We thank the interviewers, Kathy Deacon, Anna Martin Carolyn Oxborough, Joanna Parsons, Rita Smith, and Judith Walton. The study was funded by grants from the European Community's Concerted Action in Epidemiology Program, the European Foundation for Osteoporosis and Bone disease, MedEuropean Foundation for Osteoporosis and Bone disease, Med-
ical Research Council, Arthritis and Rheumatism Council and the East Anglian Health Authority.

1 Winner SJ, Morgan CA, Grimley Evans J. Perimenopausal risk of falling and incidence of distal forearm fracture. $B M F$ 1989;298:1486-8.

2 Torgerson DJ, Garton MJ, Reid DM. Falling and perimenopausal women. Age Ageing 1993;22:59-64.

3 Miller SWM, Grimley Evans J. Fractures of the distal forearm in Newcastle: an epidemiological survey. Age Ageing 1985;
14:155-8.

4 Owen RA, Melton LJIII, Johnson KA, Ilstrup DM, Riggs BL. Incidence of Colles' fracture in a North American community. Am ₹ Public Health 1982;72:605-7.

5 Donaldson LJ, Cook A, Thomson RG. Incidence of fractures in a geographically defined population. $\mathcal{f}$ Epidemiol Community Health 1990;44:241-5.

6 Cummings SR, Nevitt MC, Kidd S. Forgetting falls. The limited accuracy of recall of falls in the elderly. $\mathcal{F} \mathrm{Am}$ Geriatr Soc 1988;36:613-6.

7 Murphy S, Khaw K, May H, Compston JE. Milk consumption and bone mineral density in middle aged and elderly women. $B M F$ 1994;308:939-41.

8 Waldron HA. Occupational health practice. 3rd ed. London: Waldron HA. Occupational

9 Larsen CF, Lauritsen J. The epidemiology of acute wrist trauma. Int f Epidemiol 1993;22:911-6. 